\section{Intravitreal triamcinolone acetonide for treatment of persistent macular oedema in branch retinal vein occlusion}

\author{
A Özkiris ${ }^{1}, C^{2}$ Evereklioglu ${ }^{1}, K^{2}$ Erkilic ${ }^{2}$ and \\ H Dogan ${ }^{2}$
}

Conclusion Intravitreal triamcinolone acetonide application is a promising approach in the treatment of persistent macular oedema due to branch retinal vein occlusion nonrespondent to laser photocoagulation. Eye (2006) 20, 13-17. doi:10.1038/sj.eye.6701803; published online 18 February 2005

Keywords: intravitreal triamcinolone acetonide; persistent macular oedema; branch retinal vein occlusion

\section{Introduction}

Branch retinal vein occlusion (BRVO) is a common retinal disease causing visual loss due to macular oedema, macular nonperfusion, and vitreous haemorrhage between the ages of 60 and 70 years. It is associated with various risk factors including systemic hypertension, diabetes mellitus, high body mass index, and inflammatory or thrombophilic conditions that may lead to retinal endothelial vascular damage. ${ }^{1-3}$ When fluorescein angiography demonstrates macular oedema with cystoid involvement of the fovea, but no capillary nonperfusion, it is presumed that the macular oedema is the cause of vision loss. ${ }^{4}$ Macular grid laser photocoagulation has been shown to be effective in the treatment of macular oedema in a large prospective multicentre randomized clinical trial of BVOS. ${ }^{5}$ After 3 years of followup, $63 \%$ of laser-treated eyes gained two or more lines of vision, compared to $36 \%$ of untreated eyes. However, some eyes may be resistant to grid laser photocoagulation. Moreover, eyes with diffuse macular oedema
${ }^{1}$ Assistant Professor of Ophthalmology, Erciyes University Medical Faculty, Kayseri, Turkey

${ }^{2}$ Professor of Ophthalmology, Erciyes University Medical Faculty, Kayseri, Turkey

Correspondence: A Özkiris, Yıldırım Beyazıt mah. Mustafa Simsek, Cad. Kardelen Apt. No: 121/16 TR-38030 Melikgazi, Kayseri, Turkey Tel: + 905325223119 Fax: + 903524374912

E-mail: aozkiris@ erciyes.edu.tr

Received: 5 April 2004 Accepted: 27 July 2004 Published online: 18 February 2005

Authors have no financial or proprietary interest in any products used in this study 
have a particularly poor prognosis despite laser treatment. ${ }^{6}$ Therefore, the failure of laser photocoagulation in these eyes has prompted interest in other treatment modalities including laser-induced chorioretinal anastomosis, ${ }^{7}$ vitrectomy, and arteriovenous decompression. ${ }^{8,9}$

Triamcinolone acetonide is a safe agent for intravitreal injection in vitrectomized and nonvitrectomized eyes. ${ }^{10,11}$ Intravitreal triamcinolone acetonide (IVTA) injection has recently been reported to be effective in macular oedema of various aetiologies. ${ }^{12-15}$ Although there are few reports regarding the treatment of macular oedema in central retinal vein occlusion (CRVO) with IVTA injection, ${ }^{16-19}$ there has been no previous study evaluating the efficacy of IVTA application on chronic macular oedema in BRVO that persists despite laser photocoagulation.

Therefore, the present study investigated the efficacy of IVTA injection in the treatment of persistent macular oedema in patients with BRVO.

\section{Patients and methods}

A total of 19 eyes of 19 patients (11 men and eight women) with persistent macular oedema due to BRVO were included in the present study. The mean age of the patients was $64.3 \pm 6.0$ years. All patients had persistent macular oedema with hyperfluorescent leakage on fundus fluorescein angiography for at least 8 months, and had received grid laser photocoagulation before IVTA injection. A detailed history of medication was obtained, and the patients were excluded from the study if they had diabetes mellitus, severe renal dysfunction, nephrotic syndrome, dysproteinaemias, or were receiving vasoactive drugs or antioxidant (Figure 1).

Intravitreal injection of triamcinolone acetonide $(8 \mathrm{mg} /$ $0.2 \mathrm{ml}$ ) was offered to treat persistent macular oedema. All patients were fully informed about the character of the treatment and informed consent was obtained from each patient. The study followed the tenets of Declaration of Helsinki. Baseline parameters were documented including best-corrected visual acuity, macular oedema map values of Heidelberg Retinal Tomograph II (HRT II) (Heidelberg Engineering GmbH, Heidelberg, Germany), and intraocular pressures. Bestcorrected visual acuity for each eye was ascertained before IVTA applications, and then all eyes were tested with the same correction throughout the follow-up period. The average visual acuity was computed by converting the value to the logarithm of minimal angle of resolution (LogMAR) equivalent, and taking the average of the LogMAR values as described by Holladay. ${ }^{20}$ All statistical calculations were performed using LogMAR values for visual acuity. IVTA injections were performed by the same surgeon (AÖ) under topical anaesthesia. The

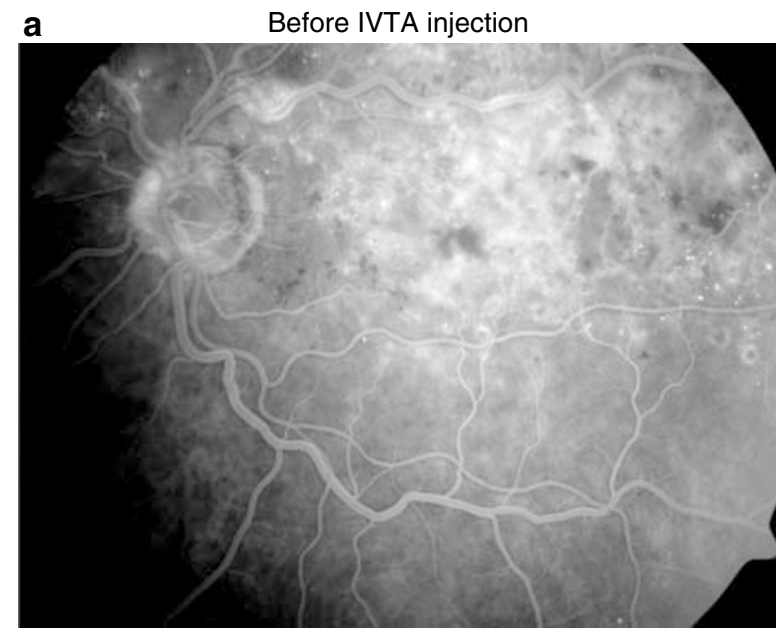

b Three months after IVTA injection.

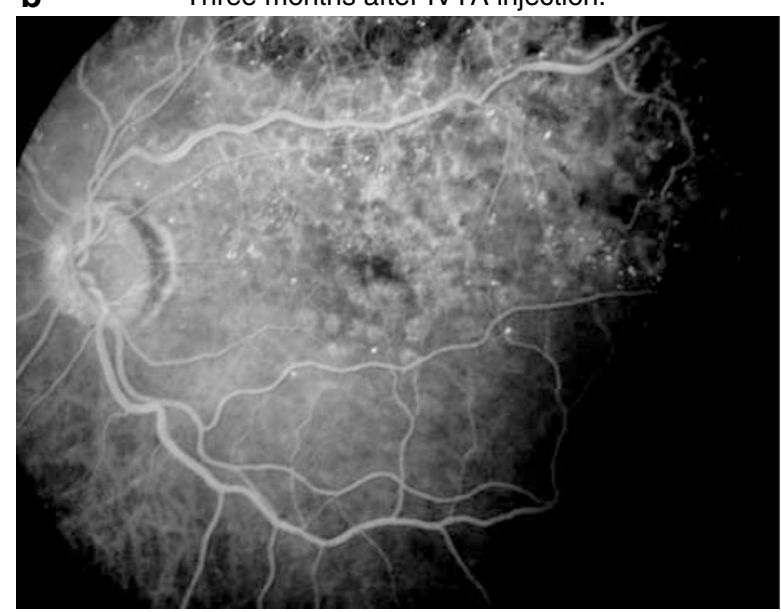

Figure 1 Late phase of fundus fluorescein angiography of the left macula of a patient showing the resolution of persistent macular oedema. (a) Before IVTA injection and (b) 3 months after IVTA injection.

standard, commercially available preparation of triamcinolone acetonide (Kenacort-A, Bristol-Myers Squibb, NY, USA) in a concentration of $40 \mathrm{mg} / \mathrm{ml}$ was used. First, the eye was anaesthetized with topical instillation of proparacaine hydrochloride $0.5 \%$ and lidocaine $4 \%$. The lid was prepped with povidone-iodine $5 \%$ applied directly to the eye, and triamcinolone acetonide was injected transconjunctivally after a paracentesis had been performed to decrease the volume of the globe. A cotton-tipped applicator was applied at the injection site immediately after the needle was removed to prevent drug egression from the needle track. Indirect ophthalmoscopy was used to confirm proper intravitreal localization of the suspension and perfusion of the optic nerve head. Topical ciprofloxacin drops were applied, and the IOP was measured $5 \mathrm{~min}$ afterwards. 
The eyes were examined after 1 week and every 4 weeks thereafter unless IOP spikes required more frequent examinations. IOPs were measured using a Goldmann applanation tonometer. Response to the treatment was monitored by visual acuity assessment, HRT II, and FFA. Potential corticosteroid-induced and injection-related complications were also recorded, if present.

The analysis of macula oedema was performed using the HRT II Macula Oedema Module. Oedema map value of HRT II was used to evaluate the changes at the macula after IVTA injection. The HRT II is a confocal laser scanning system that requires a series of optical section images at different locations of the focal plane. Technical details of the instrument have been described elsewhere. ${ }^{21}$ The patient's macula was focused on the monitor screen by adjusting the location of the focal plane, the best focus being directly related to the subject's refractive error. The $670 \mathrm{~nm}$ wavelength diode laser was used to image the macula using a $15^{\circ} \times 15^{\circ}$ field of view. The total scan depth was adjusted according to the thickness of the structure to be analysed from 0.50 to $4.00 \mathrm{~mm}$.

\section{Statistical analysis}

Results are presented as mean \pm SD. Statistical evaluation of the data was performed with two-way ANOVA. A difference was considered statistically significant when the $P$-value was lower than 0.05 .

\section{Results}

All patients had persistent macular oedema involving the centre of the macula with a mean duration of $12.6 \pm 3.0$ months (range; 8-19 months). Before intravitreal triamcinolone injection, all eyes had received an average of 1.3 laser sessions (range; $1-3$ sessions). Pre- and posttreatment visual acuities are presented in Table 1 . The mean visual acuity improved significantly from $1.01 \pm 0.16$ at baseline to a maximum of $0.55 \pm 0.22$ LogMAR during follow-up. There were statistically significant differences in mean visual acuities after IVTA injection when compared with pretreatment values (for each, $P<0.001$ ). After intravitreal injection, visual acuity increased in 17 of 19 eyes and remained unchanged in the remaining two eyes. Maximal increase in visual acuity was observed between the 1st and 3rd months after intravitreal injection.

The mean oedema map value before IVTA injection was $2.1 \pm 0.2$ (range; 1.7-2.7). After IVTA injections, it was $1.5 \pm 0.4$ (range; $1.1-1.9$ ), $1.6 \pm 0.3$ (range; 1.0-2.1), and $1.6 \pm 0.4$ (range; $1.1-2.3$ ) at the $1-, 3$-month, and last visit follow-up examinations, respectively. All eyes showed a reduction in macular oedema map value after IVTA injection. The mean reduction of oedema map values at 1-, 3- month, and last visit follow-up examinations was $28.5,23.8$, and $23.8 \%$, respectively and the differences were statistically significant when compared with preinjection values (for each, $P<0.001$ ).

IOPs of the patients before and after intravitreal injections are shown in Table 1. The mean IOP before

Table 1 Pre- and postinjection visual acuities and IOPs of the patients

\begin{tabular}{|c|c|c|c|c|c|c|c|c|}
\hline \multirow[t]{2}{*}{ Case } & \multicolumn{4}{|c|}{ Visual acuity } & \multicolumn{4}{|c|}{ IOPs $(m m H g)$} \\
\hline & $P I$ & $1 \mathrm{mo}$ & $3 \mathrm{mos}$ & $L V$ & PI & $1 \mathrm{mo}$ & $3 \mathrm{mos}$ & $L V$ \\
\hline 1 & $20 / 200$ & $20 / 50$ & $20 / 50$ & $20 / 63$ & 8 & 10 & 9 & 9 \\
\hline 2 & $20 / 200$ & $20 / 80$ & $20 / 80$ & $20 / 80$ & 15 & 14 & 16 & 15 \\
\hline 3 & $20 / 400$ & $20 / 100$ & $20 / 100$ & $20 / 100$ & 20 & 26 & 19 & 18 \\
\hline 4 & $20 / 200$ & $20 / 100$ & $20 / 100$ & $20 / 100$ & 16 & 23 & 19 & 15 \\
\hline 5 & $20 / 200$ & $20 / 63$ & $20 / 63$ & $20 / 63$ & 12 & 21 & 19 & 19 \\
\hline 6 & $20 / 200$ & $20 / 100$ & $20 / 100$ & $20 / 100$ & 11 & 19 & 18 & 16 \\
\hline 7 & $20 / 200$ & $20 / 40$ & $20 / 40$ & $20 / 40$ & 13 & 16 & 14 & 14 \\
\hline 8 & $20 / 200$ & $20 / 80$ & $20 / 80$ & $20 / 100$ & 13 & 15 & 14 & 14 \\
\hline 9 & $20 / 100$ & $20 / 40$ & $20 / 40$ & $20 / 50$ & 16 & 22 & 20 & 18 \\
\hline 10 & $20 / 80$ & $20 / 32$ & $20 / 32$ & $20 / 32$ & 12 & 14 & 13 & 12 \\
\hline 11 & $20 / 200$ & $20 / 40$ & $20 / 40$ & $20 / 40$ & 15 & 17 & 16 & 14 \\
\hline 12 & $20 / 400$ & $20 / 100$ & $20 / 100$ & $20 / 200$ & 17 & 20 & 18 & 16 \\
\hline 13 & $20 / 400$ & $20 / 100$ & $20 / 100$ & $20 / 100$ & 19 & 24 & 22 & 22 \\
\hline 14 & $20 / 200$ & $20 / 80$ & $20 / 80$ & $20 / 80$ & 12 & 15 & 15 & 14 \\
\hline 15 & $20 / 200$ & $20 / 200$ & $20 / 200$ & $20 / 200$ & 9 & 18 & 23 & 18 \\
\hline 16 & $20 / 200$ & $20 / 63$ & $20 / 63$ & $20 / 80$ & 12 & 17 & 17 & 16 \\
\hline 17 & $20 / 200$ & $20 / 50$ & $20 / 50$ & $20 / 50$ & 18 & 23 & 22 & 19 \\
\hline 18 & $20 / 200$ & $20 / 200$ & $20 / 200$ & $20 / 200$ & 6 & 9 & 13 & 12 \\
\hline 19 & $20 / 200$ & $20 / 50$ & $20 / 63$ & $20 / 63$ & 14 & 18 & 16 & 15 \\
\hline
\end{tabular}

IOP: intraocular pressure; PI: preinjection; mo: month; LV: last visit. 
IVTA injection was $13.5 \pm 3.6 \mathrm{mmHg}$, and it was $17.9 \pm 4.6,17.0 \pm 3.5$, and $15.5 \pm 3.0 \mathrm{mmHg}$ at the 1-, 3-month, and last visit examinations, respectively, and the differences were statistically significant when compared with preinjection IOPs. Only one eye demonstrated a persistent IOP elevation, but was successfully treated with topical antiglaucomatous medications. No other injection- or corticosteroid-related complications were observed during the follow-up period of 6.2 months.

\section{Discussion}

Macular oedema is a common cause of visual loss in patients with BRVO. A disruption of the inner bloodretinal barrier is due to elevation of distal intravascular pressures, and is often associated with significant hyperfluorescent leakage and a relatively poor prognosis. This vasogenic oedema is less likely to resolve spontaneously and laser photocoagulation should be considered if macular oedema persists. ${ }^{22}$ The Branch Retinal Vein Occlusion Study evaluated the effectiveness of grid laser photocoagulation in reducing macular oedema. They have reported that treated eyes were twice as likely to improve two or more lines with an achievement of a visual acuity of $20 / 40$ or better when compared with untreated control eyes. ${ }^{5}$

Another approach for the treatment of macular oedema is to reroute the blood flow by a laser-induced chorioretinal venous anastomosis, but this technique may be associated with some complications, including fibrovascular proliferation, haemorrhage, and tractional retinal detachment. ${ }^{23}$ Vitrectomy with mechanical separation of the arteriovenous sheath at the site of occlusion is another option in the treatment of macular oedema in patients with BRVO. ${ }^{8,9}$ Intravitreal tissue plasminogen activator administration has also been tested with mixed results. ${ }^{24}$

Inflammatory mediators are implicated in the pathogenesis of macular oedema. Corticosteroids inhibit phospholipase $\mathrm{A}_{2}$ and subsequent release of arachidonic acid, which is the precursor of prostaglandins and leukotrienes. Corticosteroids also downregulate the production of vascular endothelial growth factor, a known permeability factor. ${ }^{25}$ Triamcinolone acetonide is a corticosteroid suspension with no known retinal toxicity when injected intravitreally and has been shown to reduce breakdown of the inner blood-retinal barrier. ${ }^{26}$ Subtenon, retrobulbar, or topical applications of corticosteroids are insufficient to deliver adequate drug levels to the vitreous and retina. Although oral prednisone delivers effective levels of intraocular steroids, systemic side effects are present that outweigh the benefit. Maximal bioavailability of triamcinolone is only possible if it is delivered intravitreally. In other words, direct intraocular injection of steroids delivers the desired drug to its target tissue in the most direct fashion without extraocular side effects. Animal studies have shown that triamcinolone crystals can be visualized in the vitreous humour for 23-41 days after the injection. ${ }^{27}$

Although all eyes in our study were treated with grid laser photocoagulation before IVTA injection, there was no corresponding improvement in their visual acuity and macular oedema did not resolve with demonstrated leakage on fundus fluorescein angiography. The results of our study showed that IVTA application was effective in the treatment of persistent macular oedema in BRVO unresponsive to previous laser photocoagulation. Visual acuity increased in the majority of the cases. In addition, quantitative measurement of oedema map value by HRT II showed a reduction in all eyes at the follow-up examinations.

There are some favourable results in a limited number of patients evaluating the efficacy of triamcinolone on macular oedema in CRVO. ${ }^{16-19}$ As macular oedema occurs with the same mechanism both in central and BRVO, we can compare our results with those in CRVO. After IVTA injection, Jonas et al ${ }^{16}$ reported an increase in the visual acuity of a patient with cystoid macular oedema due to CRVO. Bynoe et al ${ }^{17}$ treated two patients with unilateral CRVO and reported that one patient recovered eight lines of visual acuity whereas the other recovered 11 lines. Greenberg et al ${ }^{18}$ demonstrated that the visual acuity of a patient with macular oedema due to CRVO improved from counting fingers to $20 / 80$ at 6 weeks after intravitreal injection. Our results were compatible with those mentioned above.

This present study has some differences from previous studies. First, it has a large case series when compared with the previous studies. Second, the dosage of IVTA was injected as treatment of macular oedema. Third, macular oedema was evaluated by HRT II before and after IVTA injection, and reduction in oedema map values was demonstrated as the efficacy of IVTA application. However, our study has two limitations. First, there was no control group, but it can be argued that the enrolled eyes serve as their own controls because the pre- and post-treatment visual acuities and oedema map values of the same patients were compared. Second, the follow-up time is relatively short, but visual and anatomic responses were clear during the follow-up time.

In conclusion, IVTA application is a safe and effective approach for the treatment of persistent macular oedema as a result of BRVO unresponsive to laser

photocoagulation. The effects occur immediately with a rapid resolution of macular oedema and the short-term results are very promising. However, further studies are 
needed to obtain the long-term results of such an application.

\section{Acknowledgements}

We thank Öznur Köse, Buket Yancar, and Yaşar Özsoy for their excellent assistance.

\section{References}

1 Rath EZ, Frank RN, Shin DH, Kim C. Risk factors for retinal vein occlusions. A case-control study. Ophthalmology 1992; 99: 509-514.

2 Klein R, Klein BE, Moss SE, Meuer SM. The epidemiology of retinal vein occlusion: the Beaver Dam Eye Study. Trans Am Ophthalmol Soc 2000; 98: 133-141.

3 Hayreh SS, Zimmerman B, McCarthy MJ, Podhajsky P. Systemic diseases associated with various types of retinal vein occlusion. Am J Ophthalmol 2001; 131: 61-77.

4 Suzuma K, Kita M, Yamana T, Ozaki S, Takagi H, Kiryu J et al. Quantitative assessment of macular edema with retinal vein occlusion. Am J Ophthalmol 1998; 126: 409-416.

5 The Branch Vein Occlusion Study Group. Argon laser photocoagulation for macular edema in branch vein occlusion. Am J Ophthalmol 1984; 98: 271-282.

6 Saika S, Tanaka T, Miyamoto T, Ohnishi Y. Surgical posterior vitreous detachment combined with gas/air tamponade for treating macular edema associated with branch retinal vein occlusion: retinal tomography and visual outcome. Graefes Arch Clin Exp Ophthalmol 2001; 239: 729-732.

7 Fekrat S, Goldberg MF, Finkelstein D. Laser-induced chorioretinal venous anastomosis for nonischemic central or branch retinal vein occlusion. Arch Ophthalmol 1998; 116: 43-52.

8 Mester U, Dillinger P. Vitrectomy with arteriovenous decompression and internal limiting membrane dissection in branch retinal vein occlusion. Retina 2002; 22: 740-746.

9 Scott IU. Vitreoretinal surgery for complications of branch retinal vein occlusion. Curr Opin Ophthalmol 2002; 13: 161-166.

10 McCuen BW, Bessler M, Tano Y, Chandler D, Machemer R. The lack of toxicity of intravitreally administered triamcinolone acetonide. Am J Ophthalmol 1981; 91: 785-788.

11 Kivilcim M, Peyman GA, El-Dessouky ES, Kazi AA, Cheema R, Hegazy H. Retinal toxicity of triamcinolone acetonide in silicone-filled eyes. Ophthalmic Surg Lasers 2000; 31: 474-478.

12 Jonas JB, Kreissig I, Degenring RF. Intravitreal triamcinolone acetonide for pseudophakic cystoid macular edema. Am J Ophthalmol 2003; 136: 384-386.

13 Gillies MC, Simpson JM, Luo W, Penfold P, Hunyor AB, Chua $\mathrm{W}$ et al. A randomized clinical trial of a single dose of intravitreal triamcinolone acetonide for neovascular age-related macular degeneration: one-year results. Arch Ophthalmol 2003; 121: 667-673.

14 Ozkiris A, Evereklioglu C, Erkilic K, Tamcelik N, Mirza E. Intravitreal triamcinolone acetonide injection as primary treatment for diabetic macular edema. Eur J Ophthalmol 2004; 14: 543-549.

15 Antcliff RJ, Spalton DJ, Stanford MR, Graham EM, Ffytche TJ, Marshall J. Intravitreal triamcinolone for uveitic cystoid macular edema: an optical coherence tomography study. Ophthalmology 2001; 108: 765-772.

16 Jonas JB, Kreissig I, Degenring RF. Intravitreal triamcinolone acetonide as treatment of macular edema in central retinal vein occlusion. Graefes Arch Clin Exp Ophthalmol 2002; 240: 782-783.

17 Bynoe LA, Weiss JN. Retinal endovascular surgery and intravitreal triamcinolone acetonide for central vein occlusion in young adults. Am J Ophthalmol 2003; 135: 382-384.

18 Greenberg PB, Martidis A, Rogers AH, Duker JS, Reichel E. Intravitreal triamcinolone acetonide for macular oedema due to central retinal vein occlusion. Br J Ophthalmol 2002; 86: $247-248$.

19 Ip MS, Kumar KS. Intravitreous triamcinolone acetonide as treatment for macular edema from central retinal vein occlusion. Arch Ophthalmol 2002; 120: 1217-1219.

20 Holladay JT. Proper method for calculating average visual acuity. J Refract Surg 1997; 13: 388-391.

21 Zambarakji HJ, Evans JE, Amoaku WM, Vernon SA. Reproducibility of volumetric measurements of normal maculae with the Heidelberg retina tomograph. $\mathrm{Br} J$ Ophthalmol 1998; 82: 884-891.

22 Dick JSB, Jampol LM, Haller JA. Macular edema. In: Ryan SJ (ed.) Retina, 3rd ed. Mosby: Philadelphia, 2001 pp 967-981.

23 McAllister IL, Douglas JP, Constable IJ, Yu DY. Laserinduced chorioretinal venous anastomosis for nonischemic central retinal vein occlusion: evaluation of the complications and their risk factors. Am J Ophthalmol 1998; 126: 219-229.

24 Glacet-Bernard A, Kuhn D, Vine AK, Oubraham H, Coscas $\mathrm{G}$, Soubrane G. Treatment of recent onset central retinal vein occlusion with intravitreal tissue plasminogen activator: a pilot study. Br J Ophthalmol 2000; 84: 609-613.

25 Kompella UB, Bandi N, Ayalasomayajula SP. Subconjunctival nano- and microparticles sustain retinal delivery of budesonide, a corticosteroid capable of inhibiting VEGF expression. Invest Ophthalmol Vis Sci 2003; 44: 1192-1201.

26 Wilson CA, Berkowitz BA, Sato Y, Ando N, Handa JT, de Juan Jr E. Treatment with intravitreal steroid reduces bloodretinal barrier breakdown due to retinal photocoagulation. Arch Ophthalmol 1992; 110: 1155-1159.

27 Scholes GN, O’Brien WJ, Abrams GW, Kubicek MF. Clearance of triamcinolone from vitreous. Arch Ophthalmol 1985; 103: 1567-1569. 